\title{
Are changes in self-rated health associated with memory decline in older adults?
}

Bendayan, R., Piccinin, A.M., Hofer, S.M., \& Muniz-Terrera, G.

1 MRC Unit for Lifelong Health and Ageing at UCL

London (United Kingdom)

Rebecca Bendayan r.bendayan@ucl.ac.uk

Graciela Muniz-Terrera g.muniz@ucl.ac.uk

2 Department of Psychology

University of Victoria

Victoria (Canada)

Andrea M. Piccinin piccinin@uvic.ca

Scott M. Hofer smhofer@uvic.ca

Running title: Cognitive decline and self-rated health

\section{Funding}

Research reported in this publication was supported by the National Institute on Aging of the National Institutes of Health under award number P01AG043362 for the Integrative Analysis of Longitudinal Studies of Aging (IALSA) research network. The content is solely the responsibility of the authors and does not necessarily represent the official views of the National Institutes of Health.

\section{Corresponding author:}

Rebecca Bendayan Ph.D.

MRC Unit for Lifelong Health and Ageing at UCL

33 Bedford Place

London WC1B 5JU

United Kingdom

r.bendayan@ucl.uc.uk

Tel.: +44 (0) 2076705716 


\title{
Are changes in self-rated health associated with memory decline in older adults?
}

\begin{abstract}
Objective. The association between patterns of change in self-rated health (SRH) and memory trajectories in older adults was examined using a systematic approach.

Method. Data from the Health Retirement Study (N=6016) and the English Study of Ageing $(\mathrm{N}=734)$ were analyzed. Individuals were grouped into five categories according to their pattern of change in SRH over eight years: stable excellent/very good/good, stable fair/poor, improvement, decline and fluctuating pattern without a trend. Memory was measured using immediate and delayed recall tests. Kruskal-Wallis, chi-squares tests, and linear mixed models were used to examine the association.

Results. Different rates of decline in memory can be identified in the different patterns of change in SRH. Those who had a stable excellent/very good/good pattern had the slowest rate of decline.

Discussion. Our findings suggest that SRH status and patterns of change could be used as a marker of cognitive decline in prevention screening programs.
\end{abstract}

Keywords: Self-Rated Health; Memory; Cognitive Decline; Older Adults 


\section{Introduction}

Self-rated health (SRH) reflects the general perception of an individual's health status and it is one of the most inclusive and informative indicators of health status (Jylhä, 2009). Moreover, it is known to be sensitive to health changes (Galenkamp et al., 2013) and has been shown to be a robust predictor of mortality and morbidity (Idler \& Benyamini, 1997; Rutledge et al., 2010). Research to date has also found a positive association between SRH and cognitive performance in older adults (Anstey \& Christensen, 2000; Earles, Connor, Smith \& Park, 1997; Hultsch, Hertzog, Small \& Dixon, 1999; Walker, Maxwell, Hogan \& Ebly, 2004) and some studies also reported that poorer SRH predicts cognitive decline (Carmelli, Swan, LaRue \& Eslinger, 1997; Sargent-Cox, Cherbuin, Sachdev \& Anstey, 2011), cognitive impairment (Bond, Dickinson, Matthews, Jagger \& Brayne, 2006) and allcause dementia (John \& Montgomery, 2013; Kato et al, 2013; Monthlaluc et al., 2011, Weisen, Frishman, Aronson \& Wassertheil-Smoller, 1998; Yip, Brayne \& Matthews, 2006).

In cognitive ageing research, most investigations have considered static baseline measures of SRH (Earles et al., 1997; John \& Montgomorey, 2013; Kato et al, 2013; Monthlaluc et al., 2011; Sargent-Cox et al., 2011 Weisen et al., 1999; Yip et al., 2006) but recent publications highlight its dynamic nature (Leinonen, Heikkinen \& Jylhä, 2001, 2002; Rohlfsen \& Kronenfeld, 2014; Vogelsang, 2014; Wilson, Elliot, Eyles \& Keller-Olaman, 2007). To date, only a few studies have examined the association between changes in SRH and cognition (Carmelli et al, 1997; Hultsch et al. 1999; Leinonen et al., 2001). For instance, Carmelli et al. (1997) considered changes in health rating and its association with cognitive change using two time points over 6 years. They identified three patterns of change in overall cognitive performance in older adults (i.e., decliners, non-changers and improvers) and found that decliners rated their health as poor at baseline and were also the only ones to show changes in SRH. Hultsch et al. (1999) examined the association between lifestyle and a 
number of cognitive tests (i.e., recall tasks, vocabulary, verbal fluency, working memory, reading comprehension, and comprehension and semantic speed) in 3 occasions over 6 years. They found that, although most of the cognitive variables (except fact recall, vocabulary and verbal fluency) and SRH were significantly associated at baseline, changes in the cognitive variables were not associated with baseline SRH or changes in SRH. Leinonen et al. (2001) identified different patterns of change in SRH between two time points with a 5 year interval between them and found that those whose psychomotor speed and perception decreased substantially also showed a decline in SRH. These inconsistencies across studies could be associated with the different cognitive domains considered, the use of only a limited number of measuring occasions to examine change or the characteristics of the samples considered. In addition, the above mentioned studies used analytical strategies (e.g., t-tests) that consider the average change of the group of individuals and do not account for between individual variability. However, each individual might have different scores at baseline and different rates of decline over time. Over the last decade, advances on longitudinal data analysis techniques have provided researchers the opportunity to explore how individuals change over time and how these changes vary between individuals (e.g., linear mixed models). Within this context, studies that examine the association between changes in SRH and changes in cognitive performance in older adults taking into account individual variability are needed.

The main aim of this paper is to examine the association between the different patterns of change in SRH and memory trajectories in older adults. In order to it, we analyse data from a nationally representative survey of US older adults, the Health Retirement Study (HRS), and replicate the statistical procedure in a nationally representative survey of English older adults, the English Longitudinal Study of Ageing (ELSA). Replication studies are essential to build scientific knowledge and recent publications have highlighted the need to 
promote systematic replication efforts (Koole \& Lakens, 2012; Open Science, 2015), especially in longitudinal studies of aging (Hofer \& Piccinin, 2009).

\section{Methods}

\section{Sample}

Data are drawn from the Health and Retirement Study (HRS) from the US, which is a biannual, longitudinal and nationally representative surveys that focus on adults aged 50 and over. Details can be found in their respective websites: http://hrsonline.isr.umich.edu/. For the analyses presented here, HRS data from 1998 (wave 4) to 2006 (wave 8) were included. Wave 4 of HRS was selected as "baseline" as 1998 is when HRS and AHEAD were fully integrated and when HRS assessment procedure matched other sister studies as the English Longitudinal Study of Ageing (ELSA). For the purpose of this study, the first wave considered will be labelled as baseline and the subsequent ones follow-ups.

For replication purposes, data from 2000 (wave 1) to 2008 (wave 5) of the sister study of HRS in England, ELSA, were also examined. Details can be found in http://www.elsaproject.ac.uk/. Both samples were restricted to respondents who were between 65 and 80 years old at the baseline and had at least three valid measurements for memory and self-rated health, following Singer and Willet (2003) recommendations. Therefore, the US sample consisted of a subsample of 6016 respondents (58.7\% women) of the HRS and the English sample consisted of a subsample of 734 respondents (42.5\% were women) of the ELSA. Relevant descriptive statistics are shown in Table 1 for HRS (Supplemental Table 1 for ELSA).

\section{PLEASE, INSERT TABLE 1 AROUND HERE}

\section{Measures}

Memory. Memory was assessed using immediate and delayed free-recall of a word list. Ten common words are presented orally to participants who are asked to remember them. The 
same four word lists versions are used in HRS and ELSA, with the initial list randomly assigned to the respondent in both studies.

Self-rated health change. In both studies, respondents were asked to rate their own health from excellent to poor. Self-rated health was originally a 5 category variable (excellent, very good, good, fair and poor), however, we recoded it at each wave into two categories: (a) excellent, very good and good, and (b) fair or poor. This dichotomization has been used in previous studies (Diehr, Thielke, Newman, Hirsch \& Tracy, 2013; Leinonen et al., 2002). Five patterns of observed change in self-rated health were identified in preliminary analyses and a variable that grouped individuals by their pattern of change between baseline and an eight year follow-up into was derived. This variable had 5 categories: stable excellent/very good/good pattern over time (EVGG); stable fair/poor pattern over time (FP); (3) improvement (IMP), from self-rated health fair/poor to excellent/very good/ good; (4) decline (DECL), from self-rated health excellent/very good/good to fair/poor; and (5) selfrated health fluctuating without a trend (FLUCT).

Covariates. Age, sex and education have been found to be associated with memory decline and self-rated health in older adults (Deary et al., 2009; Mirowsky \& Ross, 2008; Piccinin et al., 2013). Therefore, models were adjusted for sex, age at baseline and education. Baseline age was centered at 65 years and three levels of education were compared: (a) less than 10 years of education; (b) between 10 and 13 years of education; and, (c) more than 13 years of education.

\section{Statistical Analyses}

Both samples were analysed separately and the same statistical procedure was followed. Differences in memory scores between SRH groups at each measurement occasion were tested using Kruskal-Wallis tests and post-hoc tests. Additional chi-square tests were 
performed to explore whether there was any association between SRH changes and baseline age, education or sex.

To explore change in immediate and delayed recall, general linear mixed models with random coefficients (Laird \& Ware, 1982) were estimated using SAS Proc Mixed (Little, Miliken, Stoup \& Wolfinger, 1996). Linear and quadratic models were examined and compared using the Bayesian Information Criterion (BIC). Conditional models were fitted to each score, adjusted for baseline age, sex and education. Categories of SRH change were dichotomized and effect coded so as the other categorical covariates.

\section{Results}

Descriptive and cross-sectional analyses

In preliminary analyses, attrition rates and missing data patterns were examined. Overall attrition rates were $18.42 \%$ for immediate recall and $18.38 \%$ for delayed recall in HRS, and $3.14 \%$ for immediate recall and $4.09 \%$ for delayed recall in ELSA. No significant differences were found in the attrition rates as a function of the pattern of change in self-rated health in both samples. In HRS, those respondents who had complete data had higher baseline scores in immediate and delayed recall, were slightly younger at baseline and were more likely to be higher-educated. However, none of these differences were found in ELSA (except for education). With regards to the descriptive statistics at baseline and follow-ups (Table 1 for HRS and supplemental Table 1 for ELSA), there was no significant association between SRH change categories and sex but a significant association with education. With regards to baseline age, EVGG was found to be significantly younger than IMP and FLUCT in HRS.

For immediate recall scores, as it can be seen in Table 1, the results showed that there were differences between the groups in each measurement occasion. Specifically, post-hoc tests showed that the differences at baseline were significant between all the groups, except between IMP and FLUCT. At each follow-up, EVGG had the highest scores and FP the 
lowest and no significant differences were found between IMP, DECL and FLUCT. However, at 4 years follow-up, IMP scores in immediate recall were significantly lower than EVGG scores although not significantly different from the other groups. Overall, similar results were found in ELSA (Supplemental Table 1), except for baseline and at 4 years follow-up where the differences between all the groups appeared to be significant.

For delayed recall scores, in each measurement occasion, EVGG had the highest scores and FP the lowest and no significant differences were found between IMP, DECL and FLUCT. In addition, no significant differences were found between FP and IMP at baseline, 2 and 4 years follow-up. As it can be seen in Supplemental Table 1, the same pattern of results was found for ELSA, except at baseline and 4 years follow up.

Overall, in both studies, cross-sectional results showed that EVGG had the greatest memory scores and FP the lowest ones at each follow up; and no significant differences between IMP, DECL and FLUCT were found in most of the measurement occasions.

\section{Linear mixed models}

To explore change in immediate and delayed recall and to examine whether it is associated with the pattern of change in SRH over the same period of time, general linear mixed models with random coefficients were fitted. Linear models are shown in Table 2 for immediate recall and delayed recall in HRS. The inclusion of quadratic terms did not improve the fit of the models.

\section{PLEASE, INSERT TABLE 2 AROUND HERE}

For the HRS sample, for both tasks, results showed that: (a) there was a significant linear decline in the scores of the immediate and delayed recall task; (b) baseline age, sex and education were significantly associated with the intercept and slope; and (c) SRH pattern was significantly associated with the intercept but not all patterns were associated with the slope. Specifically, older individuals at baseline performed worse in both memory tests and declined 
at a faster rate than younger individuals. Women performed better at baseline and declined at a slower rate than men. Education was positively associated with baseline performance and individuals with 10 to 13 years of education declined at a slower rate than those who had fewer years of education. However, those with 14 or more years or education appeared to decline faster.

With regards to the groups of SRH change, individuals in the EVGG group performed better at baseline compared to all the other groups, followed by DECL, FLUCT, IMP and FP. For the immediate recall task, the only significant difference was in the rate of decline for DECL compared to EVGG, those who declined showed a faster decline in their memory scores over time. For the delayed recall task, the EVGG group had a significantly slower decline compared to FP, DECL and FLUCT.

For ELSA sample (Supplemental Table 2), no linear change was found for both tasks. Quadratic models were also explored and did not provide better fit indexes. However, as it was found for HRS, age and education were associated with baseline memory scores but no significant differences were found for sex and SRH groups.

\section{Discussion}

The main aim of this paper was to examine the association between the different patterns of change in SRH and memory trajectories over eight years in samples of US and English older adults.

From a cross-sectional perspective, in both samples, individuals who rated their own health as excellent, very good and good in a stable pattern had the highest memory scores and those who rated their own health as fair or poor in a stable pattern over time had the lower scores in both memory tasks. Moreover, in general, no differences were found between the individuals who had an improving, declining or fluctuating pattern in SRH over time. These results are consistent with previous research which has found that there is a positive 
association between SRH and cognitive performance in older adults (Anstey \& Christensen, 2000; Earles et al., 1997; Hultsch et al., 1999; Walker et al., 2004).

From a longitudinal perspective, in both samples, results showed that, for the immediate recall test, individuals whose SRH declined over time also showed a faster decline in their memory scores over time. For the delayed recall test, those individuals who rated their health as excellent, very good and good in a stable pattern over time declined slower than those who had a fair or poor stable pattern, declining or fluctuating SRH pattern over time. In general, the association between decline in SRH and decline in cognition provides some evidence that supports earlier studies suggestion of SRH as a useful predictor of cognitive decline (Carmelli et al., 1997; Earles et al., 1997; Hultsch et al., 1999; Sargent-Cox et al., 2011). However, some of these studies considered SRH only at baseline (Sargent-Cox et al., 2011) or only used two (Carmelli et al., 1997; Earles et al., 1997) or three measurement occasions (Hultsch et al., 1999). In addition, the present study focused on general population and not on clinical samples with cognitive impairment or dementia as some of the cited studies, and therefore, future research should examine whether changes in SRH are also predictive of cognitive impairment and all-cause dementia.

Perhaps one of the most interesting results is the distinction of speed of decline as a function of the pattern of SRH over time. Specifically, for the delayed recall task, there were significant differences in the rate of decline between those who had an excellent, very good and good stable pattern, fair or poor stable pattern, a declining or a fluctuating SRH pattern over time. Although several studies have identified these different patterns of change in SRH in older adults and associated them with health outcomes (Leinonen et al., 2002; Vogelsang, 2014), the present study is the first, to our knowledge, to have examined how these patterns can predict rate of decline in memory in older adults. Our results suggest that reporting changes in our own perception of health might be a good indicator of cognitive decline and, 
within this context, it would be interesting to examine if these changes could be an early symptom of preclinical dementia. This would be in the line with Jylhä (2009) conceptual model of SRH. She highlights that a unique source of information is provided by the body sensations which are directly available to the individual and these sensations might be a reflection of physiological dysregulations. The fact that decline in memory has been found to be directly associated with decline in SRH could be due to different reasons. A possible explanation could be that there are common underlying mechanisms which drive both declines, or maybe the decline in SRH could be a reflection of the own perception of change in general cognitive performance. Further research to detangle the possible causes that might be driving both changes in older adults is needed.

One of the strengths of this study was the use of SRH as a measure of general health as previous research has found SRH an adequate proxy to evaluate overall health in older adults (Galenkamp et al., 2013; Idler \& Benyamini, 1997; Jylhä, 2009; Sargent-Cox, Anstey \& Luszcz, 2010; Vogelsang, 2014) even when compared with objective measures of health (Lima-Costa et al., 2011; Wu et al., 2013). According to the SRH conceptual model proposed by Jylhä (2009), self-ratings of health involve a cognitive process that accounts for culturally and historically varying conceptions of health, reference groups, health expectations, cultural conventions in the use of the scale, and it does not only reflect diagnosed health conditions but very early signs of conditions which may not be yet diagnosed. Our findings suggest that $\mathrm{SRH}$, in general, and SRH patterns of change, in particular, could be used as a marker of cognitive decline. However, it should be noted that as self-ratings of health involve a cognitive process, these ratings could be compromised in individuals who are already experiencing decline. Therefore, future studies should not only further examine the association between changes in SRH and cognitive impairment but also explore and compare the predictive value of SRH changes and changes in objective measures of health considering 
cognitively intact and cognitively impaired individuals. Some studies have further questioned the comparability of SRH across cultures (Jylhä, Guralnik, Ferruci, Jokela \& Heikkinen, 1998) and that might be a reason of some of the slightly different results between the English and US sample. It would be extremely interesting to perform future studies with other countries to further our understanding of this kind of issues. However, the main aim of the study was to further our understanding of this association using a systematic approach, but the comparison of both samples was not intended.

Moreover, from a methodological point of view it is interesting that our crosssectional findings are very similar in both samples but some differences arise when longitudinal results were examined. Replications of longitudinal studies are specially challenging as some characteristics of the studies cannot be exactly replicated (for example, mortality follow-ups or environmental and cultural influences); therefore, some authors have suggested the inclusion of a greater number of studies to minimize the effects of this variability between studies (Hofer \& Piccinin, 2009). In this line, future replications of the present study with other large longitudinal studies are needed. Furthermore, the slight differences that were found between those respondents that had complete data and those that did not could be associated to the fact that the sample consists mainly of those individuals who are generally maintaining their cognitive function over time. This limitation has been previously addressed when exploring change in older adults' studies and it makes the inferences of these studies conditional on the probability of surviving and remaining in the study (Hofer \& Sliwinski, 2006). In addition, it has to be noted that the English sample was smaller than the US one, and therefore, some power issues might be affecting the English data. Finally, the present study focused in memory measures, immediate and delayed recall tasks, as they have been shown be good measures to identify cognitive decline even in young old adults (e.g., Schönknecht, Pantel, Kruse \& Schröder, 2005). However, further research 
should replicate the present study with measures of processing speed or other cognitive measures.

To sum up, there is a significant association between the different patterns of change in SRH and memory trajectories in older adults. More specifically, different rates of decline in memory can be identified in the different patterns of SRH over time. Those who had an excellent, very good and good stable pattern of SRH had the slowest rate of decline compared to those who had a fair or poor stable pattern, declining or fluctuating SRH pattern over time. These results suggest that changes in SRH in older adults might be considered an indicator of cognitive decline and therefore, prevention and screening programs should be encouraged to use this easy, inexpensive and broadly used measure to identify possible pre-clinical dementia.

\section{Acknowledgements}

We would like to acknowledge the Health and Retirement Study, which is conducted by the Institute for Social Research at the University of Michigan, with grants from the National Institute on Aging (U01AG09740) and the Social Security Administration.

We would also like to acknowledge the English Longitudinal Study of Ageing (ELSA). The data were made available through the UK Data Archive. ELSA was developed by a team of researchers based at the NatCen Social Research, University College London and the Institute for Fiscal Studies. The data were collected by NatCen Social Research. The funding is provided by the National Institute of Aging in the United States, and a consortium of UK government departments co-ordinated by the Office for National Statistics. The developers and funders of ELSA and the Archive do not bear any responsibility for the analyses or interpretations presented here.

\section{Conflict of interest statement}

The authors declare that there are no conflicts of interest. 


\section{References}

Anstey, K., \& Christensen, H. (2000). Education, activity, health, blood pressure and apolipoprotein E as predictors of cognitive change in old age: a review. Gerontology, 46(3), 163-177.

Bond, J., Dickinson, H. O., Matthews, F., Jagger, C., Brayne, C., \& CFAS, M. (2006). Selfrated health status as a predictor of death, functional and cognitive impairment: a longitudinal cohort study. European Journal of Ageing, 3(4), 193-206.

Carmelli, D., Swan, G. E., LaRue, A., \& Eslinger, P. J. (1997). Correlates of change in cognitive function in survivors from the Western Collaborative Group Study. Neuroepidemiology, 16(6), 285-295.

Deary, I. J., Corley, J., Gow, A. J., Harris, S. E., Houlihan, L. M., Marioni, R. E., ... \& Starr, J. M. (2009). Age-associated cognitive decline. British medical bulletin, 92(1), 135152.

Diehr, P. H., Thielke, S. M., Newman, A. B., Hirsch, C., \& Tracy, R. (2013). Decline in health for older adults: five-year change in 13 key measures of standardized health. The Journals of Gerontology Series A: Biological Sciences and Medical Sciences, 68(9), 1059-1067.

Earles, J. L., Connor, L. T., Smith, A. D., \& Park, D. C. (1997). Interrelations of age, selfreported health, speed, and memory. Psychology and Aging, 12(4), 675.

Galenkamp, H., Deeg, D. J., Huisman, M., Hervonen, A., Braam, A. W., \& Jylhä, M. (2013). Is self-rated health still sensitive for changes in disease and functioning among nonagenarians?. The Journals of Gerontology Series B: Psychological Sciences and Social Sciences, gbt066. 
Hofer, S. M., \& Piccinin, A. M. (2009). Integrative data analysis through coordination of measurement and analysis protocol across independent longitudinal studies. Psychological methods, 14(2), 150.

Hofer, S. M., \& Sliwinski, M. J. (2006). Design and analysis of longitudinal studies on aging. Handbook of the Psychology of Aging, 6, 15-37.

Hultsch, D. F., Hertzog, C., Small, B. J., \& Dixon, R. A. (1999). Use it or lose it: engaged lifestyle as a buffer of cognitive decline in aging?. Psychology and Aging, 14(2), 245.

Idler, E. L., \& Benyamini, Y. (1997). Self-rated health and mortality: a review of twentyseven community studies. Journal of Health and Social Behavior, 21-37.

John, P., \& Montgomery, P. (2013). Does self-rated health predict dementia?. Journal of Geriatric Psychiatry and Neurology, 26(1), 41-50.

Jylhä, M. (2009). What is self-rated health and why does it predict mortality? Towards a unified conceptual model. Social Science \& Medicine, 69(3), 307-316.

Jylhä, M., Guralnik, J. M., Ferrucci, L., Jokela, J., \& Heikkinen, E. (1998). Is self-rated health comparable across cultures and genders?. The Journals of Gerontology Series B: Psychological Sciences and Social Sciences, 53(3), S144-S152.

Kato, K., Zweig, R., Schechter, C. B., Verghese, J., Barzilai, N., \& Atzmon, G. (2013). Personality, self-rated health, and cognition in centenarians: Do personality and selfrated health relate to cognitive function in advanced age? Aging (Albany NY), 5(3), 183.

Koole, S. L., \& Lakens, D. (2012). Rewarding replications a sure and simple way to improve psychological science. Perspectives on Psychological Science, 7(6), 608-614.

Laird, N. M., \& Ware, J. H. (1982). Random effects models for longitudinal data. Biometrics, 38, 963-974. 
Leinonen, R., Heikkinen, E., \& Jylhä, M. (2001). Predictors of decline in self-assessments of health among older people - a 5-year longitudinal study. Social Science \& Medicine, 52(9), 1329-1341.

Leinonen, R., Heikkinen, E., \& Jylhä, M. (2002). Changes in health, functional performance and activity predict changes in self-rated health: a 10-year follow-up study in older people. Archives of Gerontology and Geriatrics, 35(1), 79-92.

Lima-Costa, M. F., Cesar, C. C., Chor, D., \& Proietti, F. A. (2012). Self-rated health compared with objectively measured health status as a tool for mortality risk screening in older adults: 10-year follow-up of the Bambui Cohort Study of Aging. American Journal of Epidemiology, 175(3), 228-235.

Littell, R. C., Milliken, G. A., Stroup, W. W., \& Wolfinger, R. D. (1996). SAS System for mixed models. Cary: SAS Institute Inc.

Mirowsky, J. \& Ross, C.E. (2008). Education and Self-Rated Health: Cumulative Advantage and its Rising Importance. Research on Aging (30), 93-122.

Montlahuc, C., Soumare, A., Dufouil, C., Berr, C., Dartigues, J. F., Poncet, M., ... \& Alpérovitch, A. (2011). Self-rated health and risk of incident dementia A communitybased elderly cohort, the 3C Study. Neurology, 77(15), 1457-1464.

Open Science, C. (2015). Psychology. Estimating the reproducibility of psychological science. Science, 349(6251), aac4716

Piccinin, A. M., Muniz-Terrera, G., Clouston, S., Reynolds, C. A., Thorvaldsson, V., Deary, I. J., ... \& Starr, J. M. (2013). Coordinated analysis of age, sex, and education effects on change in MMSE scores. The Journals of Gerontology Series B: Psychological Sciences and Social Sciences, 68(3), 374-390. 
Rohlfsen, L. S., \& Kronenfeld, J. J. (2014). Gender Differences in Trajectories of Self-Rated Health in Middle and Old Age An Examination of Differential Exposure and Differential Vulnerability. Journal of Aging and Health, 26(4), 637-662.

Rutledge, T., Linke, S. E., Johnson, B. D., Bittner, V., Krantz, D. S., Whittaker, K. S., ... \& Vido, D. A. (2010). Self-rated versus objective health indicators as predictors of major cardiovascular events: the NHLBI-sponsored Women's Ischemia Syndrome Evaluation. Psychosomatic Medicine, 72(6), 549.

Sargent-Cox, K. A., Anstey, K. J., \& Luszcz, M. A. (2010). Patterns of longitudinal change in older adults' self-rated health: The effect of the point of reference. Health Psychology, $29(2), 143$.

Sargent-Cox, K., Cherbuin, N., Sachdev, P., \& Anstey, K. J. (2011). Subjective health and memory predictors of mild cognitive disorders and cognitive decline in ageing: the Personality and Total Health (PATH) through Life Study. Dementia and Geriatric Cognitive Disorders, 31(1), 45-52.

Schönknecht, P., Pantel, J., Kruse, A., \& Schröder, J. (2005). Prevalence and natural course of aging-associated cognitive decline in a population-based sample of young-old subjects. American Journal of Psychiatry, 162(11), 2071-2077.

Singer, J. D., \& Willett, J. B. (2003). Applied Longitudinal Data Analysis: Modeling Change and Event Occurrence. Oxford University Press.

Vogelsang, E. M. (2014). Self-rated health changes and oldest-old mortality. The Journals of Gerontology Series B: Psychological Sciences and Social Sciences, gbu013.

Walker, J. D., Maxwell, C. J., Hogan, D. B., \& Ebly, E. M. (2004). Does Self-Rated Health Predict Survival in Older Persons with Cognitive Impairment? Journal of the American Geriatrics Society, 52(11), 1895-1900. 
Weisen, S. F., Frishman, W. H., Aronson, M. K., \& Wassertheil-Smoller, S. (1998). Selfrated health assessment and development of both cardiovascular and dementing illnesses in an ambulatory elderly population: a report from the Bronx Longitudinal Aging Study. Heart disease (Hagerstown, Md.), 1(4), 201-205.

Wilson, K., Elliott, S. J., Eyles, J. D., \& Keller-Olaman, S. J. (2007). Factors affecting change over time in self-reported health. Canadian Journal of Public Health/Revue Canadienne de Sante'e Publique, 154-158.

Wu, S., Wang, R., Zhao, Y., Ma, X., Wu, M., Yan, X., \& He, J. (2013). The relationship between self-rated health and objective health status: a population-based study. $B M C$ Public Health, 13(1), 320-320.

Yip, A. G., Brayne, C., \& Matthews, F. E. (2006). Risk factors for incident dementia in England and Wales: The Medical Research Council Cognitive Function and Ageing Study. A population-based nested case-control study. Age and Ageing, 35(2), 154160. 
Table1.

HRS sample descriptive statistics and means (M) and standard deviations (SD) for immediate and delayed recall for each group of SRH change from baseline to 8 years follow-up. Percentages for categorical variables are provided.

\begin{tabular}{|c|c|c|c|c|c|c|c|}
\hline & Total & EVGG & FP & IMP & DECL & FLUCT & \\
\hline$N$ & 6016 & $\begin{array}{l}2760 \\
(45.9 \%)\end{array}$ & $\begin{array}{l}689 \\
(11.5 \%)\end{array}$ & $\begin{array}{l}344 \\
(5.7 \%)\end{array}$ & $\begin{array}{l}976 \\
(16.2 \%)\end{array}$ & $\begin{array}{l}1247 \\
(20 \%)\end{array}$ & \\
\hline Sex (Female) & $58.7 \%$ & $58.7 \%$ & $62.8 \%$ & $56.1 \%$ & $58.1 \%$ & $57.7 \%$ & $\chi^{2}(4)=6.49 ; p=.16$ \\
\hline Education & & & & & & & $\chi^{2}(8)=408.40 ; p<.001$ \\
\hline Less 10 years & $18.2 \%$ & $9.7 \%$ & $34.3 \%$ & $29.1 \%$ & $18.3 \%$ & $25.1 \%$ & \\
\hline $10-13$ years & $51.9 \%$ & $52 \%$ & $48.3 \%$ & $54.1 \%$ & $16.6 \%$ & $15.5 \%$ & \\
\hline+14 years & $29.9 \%$ & $38.3 \%$ & $17.4 \%$ & $16.9 \%$ & $20.9 \%$ & $15.6 \%$ & \\
\hline Baseline age & $\begin{array}{l}71.41 \\
(4.46)\end{array}$ & $\begin{array}{l}70.81 \\
(4.32)\end{array}$ & $\begin{array}{l}71.56 \\
(4.54)\end{array}$ & $\begin{array}{l}72.17 \\
(4.51)\end{array}$ & $\begin{array}{l}72.20 \\
(4.56)\end{array}$ & $\begin{array}{l}71.83 \\
(4.47)\end{array}$ & $\mathrm{K}-\mathrm{W}(4)=98.01 ; p<.001$ \\
\hline \multicolumn{8}{|l|}{ Immediate recall } \\
\hline Baseline & $\begin{array}{l}5.49 \\
(1.71)\end{array}$ & $\begin{array}{l}5.88 \\
(1.60)\end{array}$ & $\begin{array}{l}4.80 \\
(1.71)\end{array}$ & $\begin{array}{l}5.13 \\
(1.66)\end{array}$ & $\begin{array}{l}5.45 \\
(1.68)\end{array}$ & $\begin{array}{l}5.15 \\
(1.76)\end{array}$ & $\mathrm{K}-\mathrm{W}(4)=327.91 ; p<.001$ \\
\hline 2 years follow-up & $\begin{array}{l}5.19 \\
(1.70)\end{array}$ & $\begin{array}{l}5.56 \\
(1.66)\end{array}$ & $\begin{array}{l}4.63 \\
(1.72)\end{array}$ & $\begin{array}{l}4.80 \\
(1.57)\end{array}$ & $\begin{array}{l}5.01 \\
(1.71)\end{array}$ & $\begin{array}{l}4.92 \\
(1.62)\end{array}$ & $\mathrm{K}-\mathrm{W}(4)=273.68 ; p<.001$ \\
\hline 4 years follow-up & $\begin{array}{l}5.01 \\
(1.71)\end{array}$ & $\begin{array}{l}5.41 \\
(1.64)\end{array}$ & $\begin{array}{l}4.39 \\
(1.64)\end{array}$ & $\begin{array}{l}4.59 \\
(1.79)\end{array}$ & $\begin{array}{l}4.81 \\
(1.67)\end{array}$ & $\begin{array}{l}4.73 \\
(1.70)\end{array}$ & $\mathrm{K}-\mathrm{W}(4)=321.93 ; p<.001$ \\
\hline 6 years follow-up & $\begin{array}{l}4.80 \\
(1.64)\end{array}$ & $\begin{array}{l}5.19 \\
(1.57)\end{array}$ & $\begin{array}{l}4.13 \\
(4.56)\end{array}$ & $\begin{array}{l}4.56 \\
(4.49)\end{array}$ & $\begin{array}{l}4.49 \\
(1.63)\end{array}$ & $\begin{array}{l}4.53 \\
(1.62)\end{array}$ & $\mathrm{K}-\mathrm{W}(4)=300.59 ; p<.001$ \\
\hline 8 years follow-up & $\begin{array}{l}4.64 \\
(1.67)\end{array}$ & $\begin{array}{l}5.05 \\
(1.60) \\
\end{array}$ & $\begin{array}{l}3.97 \\
(1.54) \\
\end{array}$ & $\begin{array}{l}4.42 \\
(1.60)\end{array}$ & $\begin{array}{l}4.28 \\
(1.59)\end{array}$ & $\begin{array}{l}4.27 \\
(1.68)\end{array}$ & $\mathrm{K}-\mathrm{W}(4)=302.16 ; \mathrm{p}<.001$ \\
\hline \multicolumn{8}{|l|}{ Delayed recall } \\
\hline Baseline & $\begin{array}{l}4.33 \\
(2.11)\end{array}$ & $\begin{array}{l}4.75 \\
(2.05)\end{array}$ & $\begin{array}{l}3.58 \\
(2.05)\end{array}$ & $\begin{array}{l}3.93 \\
(3.02)\end{array}$ & $\begin{array}{l}4.25 \\
(2.13)\end{array}$ & $\begin{array}{l}4.01 \\
(2.09)\end{array}$ & $\mathrm{K}-\mathrm{W}(4)=262.77 ; p<.001$ \\
\hline 2 years follow-up & $\begin{array}{l}4.06 \\
(2.06)\end{array}$ & $\begin{array}{l}4.49 \\
(2.01)\end{array}$ & $\begin{array}{l}3.40 \\
(1.99)\end{array}$ & $\begin{array}{l}3.51 \\
(2.11)\end{array}$ & $\begin{array}{l}3.83 \\
(2.11)\end{array}$ & $\begin{array}{l}3.77 \\
(1.95)\end{array}$ & $\mathrm{K}-\mathrm{W}(4)=261.05 ; p<.001$ \\
\hline 4 years follow-up & $\begin{array}{l}3.88 \\
(2.08)\end{array}$ & $\begin{array}{l}4.34 \\
(2.03)\end{array}$ & $\begin{array}{l}3.11 \\
(1.98)\end{array}$ & $\begin{array}{l}3.33 \\
(2.07)\end{array}$ & $\begin{array}{l}3.57 \\
(2.07)\end{array}$ & $\begin{array}{l}3.67 \\
(2.02)\end{array}$ & $\mathrm{KW}(4)=298.48 ; p<.001$ \\
\hline 6 years follow-up & $\begin{array}{l}3.60 \\
(1.99)\end{array}$ & $\begin{array}{l}4.06 \\
(1.94)\end{array}$ & $\begin{array}{l}2.92 \\
(1.86)\end{array}$ & $\begin{array}{l}3.26 \\
(1.94)\end{array}$ & $\begin{array}{l}3.17 \\
(2.01)\end{array}$ & $\begin{array}{l}3.27 \\
(1.90)\end{array}$ & $\mathrm{K}-\mathrm{W}(4)=286.53 ; p<.001$ \\
\hline 8 years follow-up & $\begin{array}{l}3.41 \\
(2.01)\end{array}$ & $\begin{array}{l}3.87 \\
(1.96)\end{array}$ & $\begin{array}{l}2.62 \\
(1.92)\end{array}$ & $\begin{array}{l}3.11 \\
(2.04)\end{array}$ & $\begin{array}{l}3.01 \\
(1.93)\end{array}$ & $\begin{array}{l}2.99 \\
(1.96)\end{array}$ & $\mathrm{K}-\mathrm{W}(4)=261.10 ; \mathrm{p}<.001$ \\
\hline
\end{tabular}


Table 2.

Immediate and delayed recall models adjusted for baseline age, sex and education, for HRS.

\begin{tabular}{|c|c|c|c|c|}
\hline & \multicolumn{2}{|c|}{ Immediate recall } & \multicolumn{2}{|l|}{ Delayed recall } \\
\hline & Estimate (SE) & $\mathrm{CI}$ & Estimate (SE) & CI \\
\hline Intercept & $4.82(.06)^{* * *}$ & $4.71,49.94$ & $3.77(.07)^{* * *}$ & $3.63, .392$ \\
\hline Time & $-.06(.009)^{* * *}$ & $-.08,-.04$ & $-.04(.01)^{* *}$ & $-.06,-.02$ \\
\hline Age_baseline & $-.06(.004)^{* * * *}$ & $-.06,-.05$ & $-.08(.005)^{* * * *}$ & $-.09,-.07$ \\
\hline Female & $.61(.03)^{* * *}$ & $.54, .69$ & $.67(.04)^{* * * *}$ & $.58, .76$ \\
\hline \multicolumn{5}{|c|}{$\begin{array}{l}\text { Education (ref } 9 \\
\text { years or less) }\end{array}$} \\
\hline $10-13$ & $.88(.05)^{* * * *}$ & $.78, .98$ & $.92(.06)^{* * * *}$ & $.80,1.04$ \\
\hline $14+$ & $1.40(.05)^{* * *}$ & $1.29,1.51$ & $1.50(.06)^{* * *}$ & $1.37,1.64$ \\
\hline \multicolumn{5}{|c|}{ SRH(ref EVGG) } \\
\hline SRH_FP & $-.65(.06)^{* * *}$ & $-.77,-.53$ & $-.73(.07)^{* * *}$ & $-.88,-.58$ \\
\hline SRH_IMP & $-.40(.08) * * *$ & $-.56,-.24$ & $-.48(.10)^{* * * *}$ & $-.68,-.28$ \\
\hline SRH_DECL & $-.20(.05) * * *$ & $-.30,-.10$ & $-.24(.06)^{* *}$ & $-.37,-.12$ \\
\hline SRH_FLUCT & $-.39(.04)^{* * * *}$ & $-.49,-.30$ & $-.37(.06)^{* * * *}$ & $-.49,-.25$ \\
\hline \multicolumn{5}{|l|}{ Slope } \\
\hline Age_baseline & $-.002(.0006)^{* * *}$ & $-.003,-.001$ & $-.003(.0008)^{* * *}$ & $-.005,-.002$ \\
\hline Female & $-.02(.005)^{* * * *}$ & $-.03,-.01$ & $-.03(.007)^{* * * *}$ & $-.05,-.02$ \\
\hline \multicolumn{5}{|l|}{$\begin{array}{l}\text { Education (ref } 9 \\
\text { years or less) }\end{array}$} \\
\hline $10-13$ & $-.01(.008)^{*}$ & $-.03,-.0007$ & $-.02(.01)^{*}$ & $-.04,-.0009$ \\
\hline $14+$ & $.007(.01)^{* * * *}$ & $-.04,-.01$ & $-.04(.01)^{* * * *}$ & $-.06,-.02$ \\
\hline \multicolumn{5}{|c|}{ SRH(ref EVGG) } \\
\hline SRH_FP & $-.01(.01)$ & $-.03, .007$ & $-.02(.01)^{*}$ & $-.04, .004$ \\
\hline SRH_IMP & $.007(.007)$ & $-.01, .03$ & $-.001(.01)$ & $-.03, .03$ \\
\hline SRH_DECL & $-.05(.008) * * *$ & $-.06,-.03$ & $-.06(.01)^{* * *}$ & $-.08,-.04$ \\
\hline SRH_FLUCT & $-.007(.007)$ & $-.02, .007$ & $-.02(.009)^{* *}$ & $-.04,-.003$ \\
\hline \multicolumn{5}{|l|}{ Variances } \\
\hline Intercept & $1.06^{* * *}$ & & $1.69^{* * *}$ & \\
\hline Slope & $.009^{* * *}$ & & $.01 * * *$ & \\
\hline Residual & $1.40 * * *$ & & $2.09^{* * *}$ & \\
\hline \multicolumn{5}{|c|}{ Fit statistics for linear models } \\
\hline$-2 \mathrm{LL}$ & 96849.2 & & 107899.4 & \\
\hline $\mathrm{BIC}$ & 96884 & & 107934.2 & \\
\hline
\end{tabular}

$* * * p<.001 * * p<.01 * p<.05$ 


\section{Supplemental Table1.}

ELSA sample descriptive statistics and means (M) and standard deviations (SD) for immediate and delayed recall for each group of SRH change from baseline to 8 years followup. Percentages for categorical variables are provided.

\begin{tabular}{|c|c|c|c|c|c|c|c|}
\hline & Total & EVGG & FP & IMP & DECL & FLUCT & \\
\hline$N$ & 734 & $\begin{array}{l}345 \\
(47 \%)\end{array}$ & $\begin{array}{l}90 \\
(12.3 \%)\end{array}$ & $\begin{array}{l}44 \\
(6 \%)\end{array}$ & $\begin{array}{l}133 \\
(18.1 \%)\end{array}$ & $\begin{array}{l}122 \\
(16.6 \%)\end{array}$ & \\
\hline Sex (Female) & $42.5 \%$ & $46.7 \%$ & $30 \%$ & $43.2 \%$ & $41.4 \%$ & $41 \%$ & $\chi^{2}(4)=8.40 ; p=.07$ \\
\hline Education & & & & & & & $\chi^{2}(8)=25.99 ; p<.001$ \\
\hline Less 10 years & $45.1 \%$ & $36.4 \%$ & $61.1 \%$ & $47.6 \%$ & $50 \%$ & $50.4 \%$ & \\
\hline $10-13$ years & $45.7 \%$ & $49.4 \%$ & $37.8 \%$ & $47.6 \%$ & $44.6 \%$ & $41.9 \%$ & \\
\hline+14 years & $9.1 \%$ & $14.2 \%$ & $1.1 \%$ & $4.8 \%$ & $5.4 \%$ & $6.8 \%$ & \\
\hline Baseline age & $\begin{array}{l}70.32 \\
(4.08) \\
\end{array}$ & $\begin{array}{l}70.14 \\
(4.15)\end{array}$ & $\begin{array}{c}69.91 \\
(3.96) \\
\end{array}$ & $\begin{array}{l}69.70 \\
(3.31) \\
\end{array}$ & $\begin{array}{l}71.11 \\
(4.02)\end{array}$ & $\begin{array}{l}70.51 \\
(4.22)\end{array}$ & $\mathrm{K}-\mathrm{W}(4)=8.33 ; p=.08$ \\
\hline \multicolumn{8}{|l|}{ Immediate recall } \\
\hline Baseline & $\begin{array}{l}5.27 \\
(1.64)\end{array}$ & $\begin{array}{l}5.42 \\
(1.57)\end{array}$ & $\begin{array}{l}4.95 \\
(1.84)\end{array}$ & $\begin{array}{l}5.20 \\
(1.78)\end{array}$ & $\begin{array}{l}5.26 \\
(1.62)\end{array}$ & $\begin{array}{l}5.10 \\
(1.63)\end{array}$ & $\mathrm{K}-\mathrm{W}(4)=8.60 ; p=.07$ \\
\hline 2 years follow-up & $\begin{array}{l}5.36 \\
(1.60)\end{array}$ & $\begin{array}{l}5.52 \\
(1.64)\end{array}$ & $\begin{array}{l}4.85 \\
(1.54)\end{array}$ & $\begin{array}{l}5.15 \\
(1.64)\end{array}$ & $\begin{array}{l}5.46 \\
(1.58)\end{array}$ & $\begin{array}{l}5.23 \\
(1.44)\end{array}$ & $\mathrm{K}-\mathrm{W}(4)=18.40 ; p<.001$ \\
\hline 4 years follow-up & $\begin{array}{l}5.30 \\
(1.56)\end{array}$ & $\begin{array}{l}5.48 \\
(1.62)\end{array}$ & $\begin{array}{l}4.97 \\
(1.31)\end{array}$ & $\begin{array}{l}5.11 \\
(2.02)\end{array}$ & $\begin{array}{l}5.12 \\
(1.33)\end{array}$ & $\begin{array}{l}5.28 \\
(1.56)\end{array}$ & $\mathrm{K}-\mathrm{W}(4)=15.22 ; p=.004$ \\
\hline 6 years follow-up & $\begin{array}{l}5.01 \\
(1.65)\end{array}$ & $\begin{array}{l}5.26 \\
(1.60)\end{array}$ & $\begin{array}{l}4.54 \\
(1.57)\end{array}$ & $\begin{array}{l}5.15 \\
(1.76)\end{array}$ & $\begin{array}{l}4.83 \\
(4.82)\end{array}$ & $\begin{array}{l}4.82 \\
(1.52)\end{array}$ & $\mathrm{K}-\mathrm{W}(4)=20.21 ; p<.001$ \\
\hline 8 years follow-up & $\begin{array}{l}4.78 \\
(1.89)\end{array}$ & $\begin{array}{l}5.09 \\
(1.79)\end{array}$ & $\begin{array}{l}4.03 \\
(2.16)\end{array}$ & $\begin{array}{l}4.63 \\
(1.75)\end{array}$ & $\begin{array}{l}4.47 \\
(1.92)\end{array}$ & $\begin{array}{l}4.83 \\
(1.77)\end{array}$ & $\mathrm{K}-\mathrm{W}(4)=26.71 ; p<.001$ \\
\hline \multicolumn{8}{|l|}{ Delayed recall } \\
\hline Baseline & $\begin{array}{l}3.82 \\
(1.89)\end{array}$ & $\begin{array}{l}3.99 \\
(1.77)\end{array}$ & $\begin{array}{l}3.55 \\
(2.11)\end{array}$ & $\begin{array}{l}3.50 \\
(2.02)\end{array}$ & $\begin{array}{l}3.83 \\
(1.89)\end{array}$ & $\begin{array}{l}3.63 \\
(1.97)\end{array}$ & $\mathrm{K}-\mathrm{W}(4)=7.33 ; p=.11$ \\
\hline 2 years follow-up & $\begin{array}{l}3.91 \\
(1.84)\end{array}$ & $\begin{array}{l}4.12 \\
(1.86)\end{array}$ & $\begin{array}{l}3.35 \\
(1.61)\end{array}$ & $\begin{array}{l}3.79 \\
(1.87)\end{array}$ & $\begin{array}{l}3.76 \\
(1.96)\end{array}$ & $\begin{array}{l}3.95 \\
(1.75)\end{array}$ & $\mathrm{K}-\mathrm{W}(4)=14.67 ; p=.005$ \\
\hline 4 years follow-up & $\begin{array}{l}3.94 \\
(1.92)\end{array}$ & $\begin{array}{l}4.15 \\
(1.85)\end{array}$ & $\begin{array}{l}3.77 \\
(1.93)\end{array}$ & $\begin{array}{l}3.88 \\
(2.08)\end{array}$ & $\begin{array}{l}3.64 \\
(1.95)\end{array}$ & $\begin{array}{l}3.82 \\
(1.99)\end{array}$ & $\mathrm{K}-\mathrm{W}(4)=8.595 ; p=.07$ \\
\hline 6 years follow-up & $\begin{array}{l}3.63 \\
(2.01)\end{array}$ & $\begin{array}{l}3.91 \\
(1.97)\end{array}$ & $\begin{array}{l}3.14 \\
(1.83)\end{array}$ & $\begin{array}{l}3.77 \\
(2.06)\end{array}$ & $\begin{array}{l}3.42 \\
(2.14)\end{array}$ & $\begin{array}{l}3.40 \\
(1.99)\end{array}$ & $\mathrm{K}-\mathrm{W}(4)=14.40 ; p=.006$ \\
\hline 8 years follow-up & $\begin{array}{l}3.25 \\
(2.13)\end{array}$ & $\begin{array}{l}3.69 \\
(2.12)\end{array}$ & $\begin{array}{l}2.46 \\
(2.11)\end{array}$ & $\begin{array}{l}3.11 \\
(2.12)\end{array}$ & $\begin{array}{l}2.73 \\
(2.01)\end{array}$ & $\begin{array}{l}3.19 \\
(2.02)\end{array}$ & $\mathrm{K}-\mathrm{W}(4)=32.021 ; p<.001$ \\
\hline
\end{tabular}


Supplemental online Table 2.

Immediate and delayed recall models adjusted for baseline age, sex and education, for ELSA.

\begin{tabular}{|c|c|c|c|c|}
\hline & \multicolumn{2}{|c|}{ Immediate recall } & \multicolumn{2}{|l|}{ Delayed recall } \\
\hline & Estimate (SE) & $\mathrm{CI}$ & Estimate (SE) & $\mathrm{CI}$ \\
\hline Intercept & $5.17(.12)^{* * * *}$ & $4.92,5.42$ & $3.78(.15)^{* * *}$ & $3.48,4.08$ \\
\hline Time & $.02(.02)$ & $-.02, .06$ & $.03(.02)$ & $-.009, .07$ \\
\hline Age_baseline & $-.04(.01)^{* * *}$ & $-.06,-.01$ & $-.06(.01)^{* * *}$ & $-.09,-.03$ \\
\hline Female & $.12(.10)$ & $-.07, .32$ & $.27(.12)^{*}$ & $.03, .51$ \\
\hline \multicolumn{5}{|c|}{$\begin{array}{l}\text { Education (ref } 9 \\
\text { years or less) }\end{array}$} \\
\hline $10-13$ & $.66(.10) * * *$ & $.45, .86$ & $.67(.21)^{* * *}$ & $.42, .92$ \\
\hline $14+$ & $1.14(.18) * * *$ & $.79,1.50$ & $1.16(.21)^{* * *}$ & $.73,1.59$ \\
\hline \multicolumn{5}{|c|}{ SRH(ref EVGG) } \\
\hline SRH_FP & $-.22(.15)$ & $-.53, .08$ & $-.19(.19)$ & $-.56, .18$ \\
\hline SRH_IMP & $-.20(.21)$ & $-.62, .21$ & $-.38(.25)$ & $-.89, .12$ \\
\hline SRH_DECL & $.10(.13)$ & $-.16, .37$ & $.06(.16)$ & $-.25, .38$ \\
\hline SRH_FLUCT & $-.12(.14)$ & $-.40, .15$ & $-.03(.17)$ & $-.37, .29$ \\
\hline \multicolumn{5}{|l|}{ Slope } \\
\hline Age_baseline & $-.008(.002)^{* * *}$ & $-.01,-.004$ & $-.009(.002)^{* * *}$ & $-.01,-.005$ \\
\hline Female & $.01(.01)$ & $-.02, .04$ & $-.02(.01)$ & $-.06, .007$ \\
\hline \multicolumn{5}{|l|}{$\begin{array}{l}\text { Education (ref } 9 \\
\text { years or less) }\end{array}$} \\
\hline $10-13$ & $-.02(.01)$ & $-.05, .01$ & $-.005(.01)$ & $-.04, .03$ \\
\hline $14+$ & $-.07(.03)^{* *}$ & $-.13,-.01$ & $-.01(.03)$ & $-.07, .04$ \\
\hline \multicolumn{5}{|c|}{ SRH(ref EVGG) } \\
\hline SRH_FP & $-.07(.02)^{* *}$ & $-.12,-.02$ & $-.08(.02) * *$ & $-.13,-.02$ \\
\hline SRH_IMP & $-.03(.03)$ & $-.10, .04$ & $-.003(.03)$ & $-.07, .07$ \\
\hline SRH_DECL & $-.06(.02)^{* *}$ & $-.11,-.01$ & $-.08(.02) * * *$ & $-.13, .03$ \\
\hline SRH_FLUCT & $-.01(.02)$ & $-.05, .03$ & $-.03(.02)$ & $-.08, .01$ \\
\hline \multicolumn{5}{|l|}{ Variances } \\
\hline Intercept & $.67 * * *$ & & $1.28^{* * *}$ & \\
\hline Slope & $.007^{* *}$ & & .003 & \\
\hline Residual & $1.67 * * *$ & & $1.91 * * *$ & \\
\hline \multicolumn{5}{|l|}{ Fit statistics } \\
\hline$-2 \mathrm{LL}$ & 12693.8 & & 13364.9 & \\
\hline $\mathrm{BIC}$ & 12720.1 & & 13391.1 & \\
\hline
\end{tabular}

